\title{
ÁRVORES MATRIZES DE Tabebuia pentaphyla (L.) Hemsl. (Ipê de El Salvador) E Caesalpinia pluviosa DC. (Sibipiruna) EM ÁREA URBANA, SELECIONADAS POR MEIO DE ÍNDICE DE IMPORTÂNCIA
}

Marcio Amaral Yamamoto; Graciela da Rocha Sobierajski; Demóstenes Ferreira da Silva Filho;

Hilton Thadeu Zarate do Couto

\section{RESUMO}

O presente trabalho utilizou conceitos de conservação genética de espécies arbóreas e índice de importância em sistema de banco de dados para avaliar a seleção de matrizes urbanas e conservação genética de indivíduos adaptados ao meio urbano. Duas espécies foram estudadas (Caesalpinia pluviosa DC. e Tabebuia pentaphylla (L.) Hemsl.) pois apresentaram a freqüência mínima para que pudessem ser determinadas as árvores matrizes. Concluiu-se que serão necessárias 50 sementes de cada uma das 50 matrizes para a conservação da diversidade genética presente. As matrizes foram locadas em um mapa do bairro e foram definidos os trajetos de coleta de sementes. Os resultados do estudo de caso mostraram a possibilidade do procedimento de conservação em curto prazo no manejo da floresta urbana.

Palavras-chave: Silvicultura urbana, seleção de árvores, sustentabilidade florestal 


\title{
MAIN TREES OF Tabebuia pentaphyla (L.) Hemsl. (Ipê de EI Slavador) AND Caesalpinia pluviosa DC. (Sibipiruna) IN URBAN AREA SELECTED BY IMPORTANCE INDEX
}

\begin{abstract}
The present work used genetic conservation concepts of arboreal species and a database system for the selection of urban head offices and it indicates solution for the individuals' genetic conservation adapted to the urban fabric. As example or case study, two species (Caesalpinia pluviosa DC. and Tabebuia pentaphylla (L.) Hemsl.) because they presented the minimum frequency so that they could be certain the main trees. It was ended that will be necessary 50 seeds of each one of the 50 head offices for the present genetic diversity conservation. The head offices were located in a neighborhood map and they were defined the itineraries of seeds collection. The results of the case study showed the possibility of the short term conservation procedure in the urban forest management.
\end{abstract}

Key words: urban forestry, tree selection, sustainable forest 


\section{INTRODUÇÃO}

A antropização dos ambientes naturais e a extinção de inúmeras espécies têm aumentado a preocupação com a Biodiversidade e a sua conservação. Segundo Castellen (2000) a fragmentação provoca a diminuição do tamanho da população que resulta em acréscimo nas taxas de endogamia e deriva genética. Esse quadro tem como conseqüência a perda de alelos raros e conseqüentemente, a diminuição da diversidade genética da espécie.

A diversidade genética em populações tem grande importância, pois permite a adaptação dos indivíduos frente às diversas pressões seletivas exercidas pelo ambiente. Considerando as áreas urbanas como sendo um sistema onde existem interações entre os organismos e os indivíduos destas populações, torna-se imprescindível a atenção com a variabilidade genética de seus indivíduos arbóreos.

Populações de árvores em áreas urbanas com baixa variabilidade genética tornam-se mais vulneráveis à infestação de pragas e doenças, o que é acentuado pelas condições de estresse provocado por esse ambiente bastante alterado.

A procedência das sementes utilizadas é fator fundamental no planejamento da Arborização Urbana, pois definirá a variabilidade genética das mudas a serem implantadas. Comumente, as sementes são coletadas em fragmentos remanescentes nas proximidades dos centros urbanos ou mesmo em calçadas.

Ao se realizar a coleta em pequenas áreas ou em árvores isoladas, há uma grande chance destas estarem se cruzando com outros indivíduos aparentados, ou até mesmo estarem se autofecundando (Sebbenn et al., 1998). Esse evento acarretará (a curto, a médio, ou a longo prazo), em problemas como, de baixa germinação e resistência (Shimizu, 2001).

A atenção em relação à procedência das sementes é ainda mais importante se o objetivo for utilizar essas árvores como futuras matrizes, pois ao se formar uma área de coleta de sementes com base genética restrita, suas progênies terão grande possibilidade de apresentar baixa adaptabilidade à mudanças do ambiente e as suas sementes apresentarão baixa porcentagem de germinação.

Como as informações sobre origem das sementes ou mudas utilizadas na Arborização Urbana nem sempre são disponíveis, e quando existem não podem ser consideradas como sendo precisas, a determinação de sua procedência fica prejudicada. Isso impossibilita as inferências sobre o grau de parentesco e a variabilidade genética existente nessas árvores.

Assim, para a manutenção da variabilidade existente na arborização, a preocupação com o tamanho efetivo das sementes a serem coletadas, torna-se prioritária. 
Existe possibilidade de aproveitamento do material colhido nas cidades como forma de conservação do patrimônio genético constituído por árvores bem adaptadas ao ambiente urbano.

O objetivo do presente trabalho foi avaliar a conservação e ampliação do patrimônio genético nas árvores urbanas por meio da utilização de conceitos de conservação genética e de índices de importância para a coleta de sementes de matrizes arbóreas em áreas urbanizadas.

\section{MATERIAL E MÉTODOS}

\section{Descrição da área de estudo}

O município de Piracicaba possui atualmente, uma população de 366.442 habitantes com uma área de $1312,30 \mathrm{~km}^{2}$, sendo $158,06 \mathrm{~km}^{2}$ em áreas urbanas e $1154,24 \mathrm{~km}^{2}$ em áreas rurais. Localiza-se nas coordenadas geográficas aproximadas de 2243'30"S e 47³8'56"W, em uma altitude de 547m (Wikipédia, 2007).

O bairro Nova Piracicaba encontra-se próximo ao rio Piracicaba, entre as coordenadas

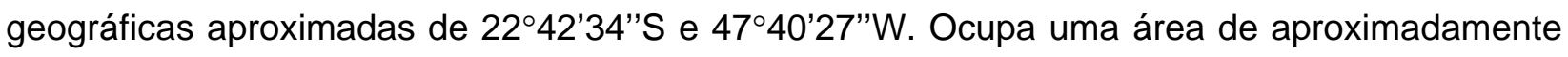
$2,57 \mathrm{~km}^{2}$, com uma população de aproximadamente 7691 habitantes de médio a alto poder aquisitivo (IBGE, 2000). Possui fluxo de veículos relativamente baixo e grande quantidade de áreas verdes com áreas de gramados e maciços de árvores. Suas ruas e avenidas possuem formas sinuosas, contendo arborização abundante que compõe os túneis-verdes.

O bairro Jardim Monumento está localizado entre as coordenadas 2242'33"S e 4740'06' $\mathrm{W}$, possuindo uma área de aproximadamente $0,53 \mathrm{~km}^{2}$. Sua densidade populacional $\left(0,66\right.$ hab/100 $\left.{ }^{2}\right)$ é maior quando comparada à da Nova Piracicaba, que possui 0,30 hab/100m ${ }^{2}$ (SILVA FILHO, 2004). A população de 3.513 habitantes possui médio poder aquisitivo. A arborização presente é variada e em menor quantidade em relação ao bairro Nova Piracicaba. Suas vias possuem disposição na forma de tabuleiro de xadrez e os quarteirões formas retangulares e de quadrados.

\section{Definição da quantidade de matrizes}

As matrizes foram determinadas entre aquelas espécies que apresentam indicações de serem aptas ao ambiente urbano. Foram definidas em uma quantidade suficiente para a manutenção da diversidade genética existente na população.

O tamanho efetivo foi estimado pelo uso da seguinte equação proposta por Cockerham 
citado por Sebbenn (2002):

$$
N_{e(1)}=0,5 /\{\theta[(n-1) / n]+[(1+F) /(2 n)]\}
$$

Sendo:

$\mathbf{N}_{\mathbf{e}(1)}$, tamanho efetivo de uma progênie;

n, número total de progênies da população, ou sementes a serem coletadas;

F, coeficiente de endogamia da população ou do conjunto de progênies;

$\boldsymbol{\theta}$, coeficiente de parentesco entre plantas dentro de progênies.

A quantidade necessária de matrizes foi calculada pela equação:

$$
\mathrm{m}=\mathrm{N}_{\mathrm{e}} / \mathrm{N}_{\mathrm{e}(1)}
$$

Onde:

m, o número de matrizes;

$\mathbf{N}_{\mathrm{e}}$, valor teórico de tamanho efetivo;

$\mathbf{N}_{\mathbf{e}(1)}$, tamanho efetivo de uma progênie;

\section{Cadastro e avaliação da arborização viária}

Foram cadastradas 1087 árvores dos bairros da área de estudo. Os dados foram coletados utilizando-se hipsômetro, trena de $30 \mathrm{~m}$, fita métrica e ficha de campo.

Adaptou-se o cadastro informatizado proposto por Silva Filho et al. (2002), que consiste em um banco de dados relacional desenvolvido no sistema gerenciador de banco de dados do software ACCESS 2000.

Os indivíduos foram avaliados com auxílio do banco de dados relacional utilizando-se das variáveis que podem ser visualizadas na Tabela 1. 
Tabela 1. Variáveis utilizadas para a avaliação dos indivíduos no banco de dados relacional classificadas por tipo.

\begin{tabular}{|c|c|c|}
\hline Variáveis quantitativas & Vari & ativas \\
\hline Contínuas (m) & Nominais & Ordinais \\
\hline $\begin{array}{c}\text { altura total } \\
\text { altura da } 1^{\mathrm{a}} \text { bifurcação } \\
\text { diâmetro da copa } \\
\text { diâmetro à altura do peito } \\
\text { distância árvore-esquina }\end{array}$ & $\begin{array}{c}\text { nome da via } \\
\text { número da casa } \\
\text { nome do bairro } \\
\text { nome comum } \\
\text { nome científico }\end{array}$ & $\begin{array}{c}\text { estado geral } \\
\text { equilíbrio } \\
\text { participação } \\
\text { recuo predial } \\
\text { Situação } \\
\text { disponibilidade } \\
\text { partes desejáveis } \\
\text { desenvolvimento } \\
\text { adaptabilidade }\end{array}$ \\
\hline
\end{tabular}

O conjunto de dados resultou na atribuição de um valor na forma de um índice para cada indivíduo cadastrado. Pode-se deduzir que um indivíduo a quem é atribuído um valor alto no índice, apresenta condições desejáveis em Silvicultura Urbana.

Esse índice, denominado Índice de Importância (li), foi calculado por meio da equação modificada de Silva Filho et al. (2002):

$$
\mathrm{li}=\mathrm{Ve} \times \mathrm{Vc} \times \mathrm{VL} \times \mathrm{Vbm}
$$

Onde,

Ve = valor da espécie;

Vc = valor de condição;

VL = valor de localização;

Vbm = valor biométrico;

O valor da espécie (Ve) foi calculado pela expressão proposta por Silva Filho et al. (2002):

$$
V e=(D i+P d+D v+A d) / 4
$$

Onde,

Di $=$ disponibilidade (disponibilidade da espécie no mercado ou com produção de mudas dispendiosa);

Pd = partes desejáveis (presença de partes desejáveis e indesejáveis);

Dv = desenvolvimento (velocidade de crescimento da espécie); 
Ad = adaptabilidade (adaptação do indivíduo no ambiente).

Foram atribuídos valores inteiros entre 1 e 4 para cada variável.

O valor de condição (Vc) adaptado de Silva Filho et al. (2002), representa o estado geral do indivíduo. Sendo, 4 (ótimo); 3 (bom); 2 (regular); 1 (péssimo) e 0 (morto).

O valor de localização (VL) foi calculado pela equação proposta por Silva Filho et al. (2002):

\section{VL = Ind x Rec x Adeq}

Onde,

Ind = presença ou ausência de outro(s) indivíduo(s) da mesma espécie (1 e 0 respectivamente);

$\mathbf{R e c}=$ presença ou ausência de recuo predial (1 e 0 respectivamente);

Adeq = adequação ou não da espécie no local (1 e 0 respectivamente).

O valor biométrico $(\mathrm{Vbm})$ foi calculado pela equação adaptada de Silva Filho et al. (2002):

$$
\text { Vbm }=(\text { DAP } \times 0,25)(\text { Alt } \times 0,25)+(H b \times 0,25)+(\text { Cop } \times 0,25)
$$

Onde,

DAP = diâmetro à altura do peito $(\mathrm{cm})$;

Alt $=$ Altura $(m)$

$\mathbf{H b}=$ altura da primeira bifurcação $(\mathrm{m})$;

Cop = diâmetro da copa $(m)$.

As matrizes foram selecionadas a partir do conjunto daqueles indivíduos, com altura maior ou igual a $4 \mathrm{~m}$, que obtiveram os maiores índices em ordem decrescente, determinados pelo banco de dados relacional. Estipulou-se a altura mínima de 4 metros visando a demarcação dos indivíduos que já atingiram a idade reprodutiva.

As variáveis biométricas foram avaliadas por meio de correlações para melhor compreensão de suas relações e avaliação de sua singularidade como variável caracterizadora para uso em área urbana. Foram usados diagramas de dispersão, equações e teste t para avaliar relações entre Diâmetro à altura do Peito (DAP), Altura da primeira bifurcação (Hb) e Diâmetro da copa (Cop). Além disso, o índice agregado (li) foi relacionado, usando o mesmo procedimento, com as variáveis biométricas para avaliação de sua eficácia como elemento para definição de matrizes.

Ainda, foram mensuradas as distâncias entre os indivíduos e as respectivas esquinas. Esses valores foram plotados em um mapa para locação espacial das matrizes. 


\section{RESULTADOS E DISCUSSÃO}

\section{Determinação da quantidade de matrizes}

Entende-se por tamanho efetivo como o índice que representa geneticamente uma amostra em relação à sua geração anterior (Vencovsky, 1987). Os valores teóricos de tamanho efetivo são determinados a partir da dimensão temporal que se objetiva atingir com a finalidade de conservação da variabilidade genética. Considera-se como sendo apropriados, os valores de tamanho efetivo de 50 e 100 (10 gerações) para a conservação em curto prazo e em longo prazo 1000 (100 gerações) (Sebbenn, 2002).

Para a determinação do tamanho efetivo de uma progênie, ou seja, o quanto representa uma árvore matriz na população, utilizou-se os seguintes parâmetros:

- $\boldsymbol{\theta}$ igual a $\mathbf{0 , 5}$. Esse valor representa o coeficiente de parentesco em árvores que foram produzidas a partir de sementes de autofecundação. Utilizou-se esse valor pois não há registro da procedência das sementes que originaram esta população e portanto, do grau de parentesco dos indivíduos.

- $\mathbf{n}$ igual a 50. Esse valor significa que devem ser coletadas 50 sementes em cada matriz determinada. Sugere-se essa quantidade relativamente baixa, pois as árvores urbanas sofrem constantemente podas, restringindo suas copas e conseqüentemente, os seus potenciais de produção de sementes. Cabral citado por Batista (1988) indica que a poda indiscriminada resulta na raridade da presença de árvores com dimensão de copa própria da espécie, o que provavelmente acarreta na diminuição de sementes.

- F igual a 0,3. O coeficiente de endogamia representa a probabilidade de dois genes de qualquer loco serem idênticos por descendência (Brewbaker, 1926). É um parâmetro que indica a probabilidade de estar havendo autofecundação. Em espécies arbóreas, encontramse valores médios de $10 \%$ (Sebbenn, 2002). Por não terem sido realizadas análises para calcular o coeficiente de endogamia dos indivíduos da população estudada, estipulou-se o valor de 0,3 .

Assim, substituindo os valores na equação 1, temos que:

$$
\mathbf{N}_{\mathrm{e}(1)}=1
$$

Esse valor significa que, na presente situação, as 50 sementes coletadas de uma árvore da população têm sua representatividade mínima, ou seja, equivalente a de um indivíduo na população.

A quantidade de matrizes $(m)$ necessárias foi definida pela equação 2 , estipulando 0 valor de tamanho efetivo da amostra $\left(\mathrm{N}_{\mathrm{e}}\right)$ igual a 50 . Esse valor é aceito como sendo suficiente 
para a prevenção de perda de alelos raros em curto prazo conforme proposto por Frankel \& Soulé (1981).

Logo, m é igual a 50.

Portanto, são necessárias 50 sementes de 50 matrizes para a conservação da diversidade genética existente, em curto prazo (10 gerações), na área estudada.

É necessário salientar que a diversidade genética existente nos indivíduos dessa população provavelmente é muito menor quando comparada àquela encontrada em ambientes naturais. Logo, a introdução de indivíduos que representem o incremento na variabilidade genética, é fundamental para que sejam garantidas a capacidade adaptativa e a otimização na "performance" da espécie no ambiente urbano.

Isso pode ser efetuado com o intercâmbio de sementes ou mudas entre municípios vizinhos ou preferencialmente com a introdução de indivíduos produzidos a partir de sementes certificadas. A certificação de sementes garante que essas foram coletadas respeitando-se as normas de coleta, portanto tais sementes possuem variabilidade genética, índice de germinação e procedência conhecidas.

\section{Avaliação do índice para determinação de matrizes}

Os diagramas de dispersão, e teste $t$ indicaram relações fracas entre as variáveis quantitativas DAP, Diâmetro da copa, Altura e Altura da primeira bifurcação, porém ocorreram significativas correlações positivas quando relacionadas ao Valor biométrico (Vbm) com relação ao DAP. Isso é esperado pois é a variável mais utilizada para valorar árvores (SILVA FILHO et al. 2002). Isso indica que esse índice agrega variáveis quantitativas e pode ser usado como base para seleção e determinação das matrizes. Essas relações estão representadas nas Figuras 1, 2, e 3. 


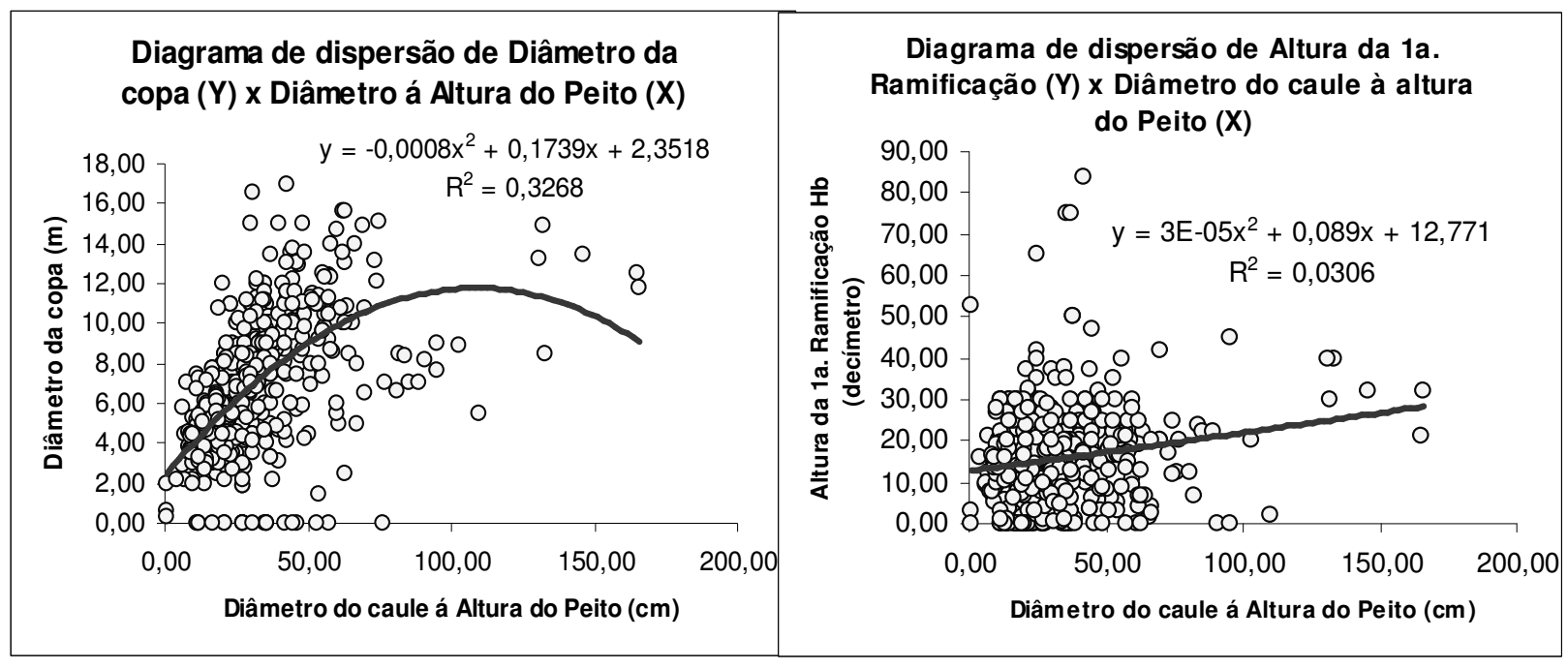

Figura 1. Diagramas de dispersão e regressões polinomiais entre variáveis obtidas de inventário de todos os indivíduos arbóreos acima de $4 \mathrm{~m}$ de altura. Asteriscos indicam significância de R2 pelo teste t a $1 \%\left({ }^{* *}\right)$ e a $5 \%\left({ }^{*}\right)$.

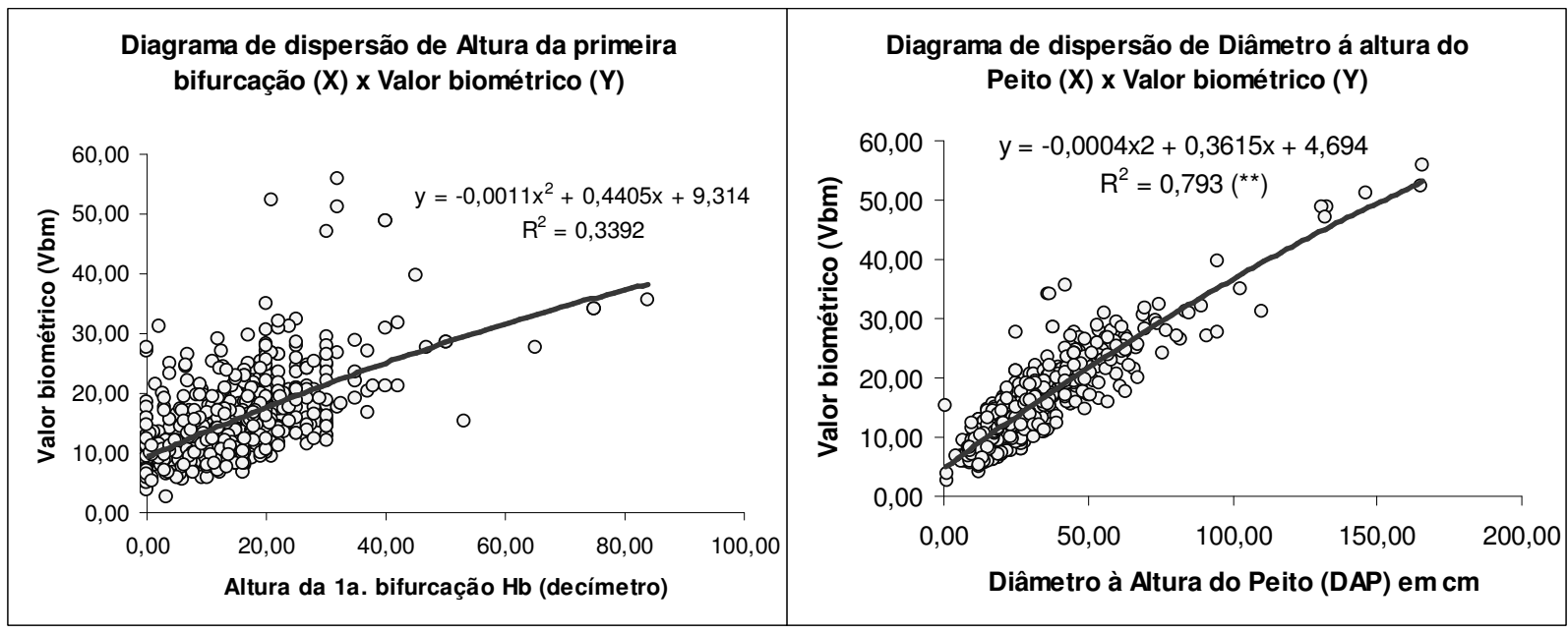

Figura 2. Diagramas de dispersão e regressões polinomiais entre variáveis obtidas de inventário de todos os indivíduos arbóreos acima de $4 \mathrm{~m}$ de altura e o valor biométrico, componente quantitativo do li - Índice de importância. Asteriscos indicam significância de R2 pelo teste t a $1 \%\left({ }^{* *}\right)$ e a $5 \%\left({ }^{*}\right)$. 


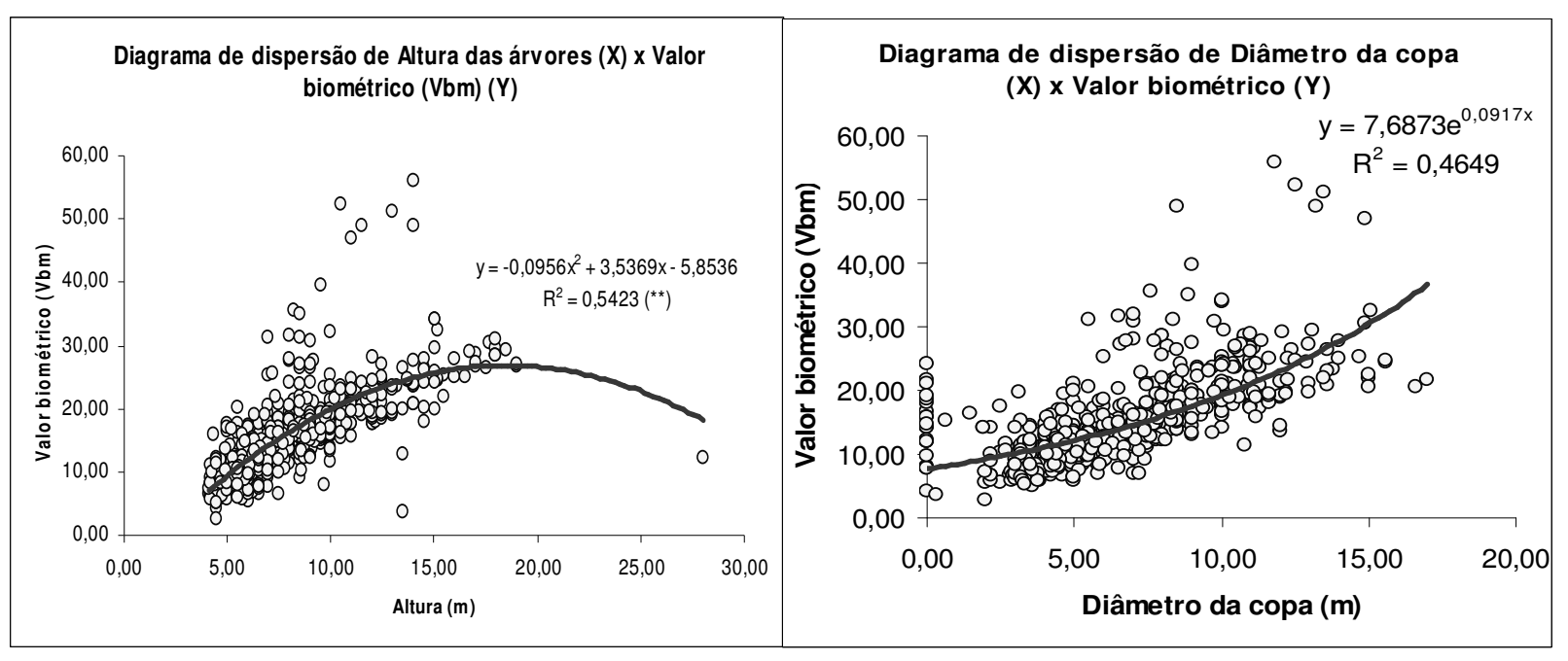

Figura 3. Diagramas de dispersão e regressões quadrática e exponencial entre variáveis obtidas de inventário de todos os indivíduos arbóreos acima de $4 \mathrm{~m}$ de altura e o valor biométrico, componente quantitativo do li Índice de importância. Asteriscos indicam significância de $\mathrm{R} 2$ pelo teste t a $1 \%\left(^{* *}\right)$ e a $5 \%\left(^{*}\right)$.

\section{Determinação das árvores matrizes}

Apenas duas espécies (Caesalpinia pluviosa DC. e Tabebuia pentaphylla (L.) Hemsl.) atingiram a freqüência absoluta mínima de 50 indivíduos, possibilitando que fossem determinadas as 50 matrizes. Para as espécies deste estudo foram escolhidos os indivíduos que apresentaram os maiores valores de Índice de importância (li) pela avaliação utilizada. Pode-se observar nas Figuras 4 e 5 os valores de li encontrados nas populações das espécies avaliadas. 


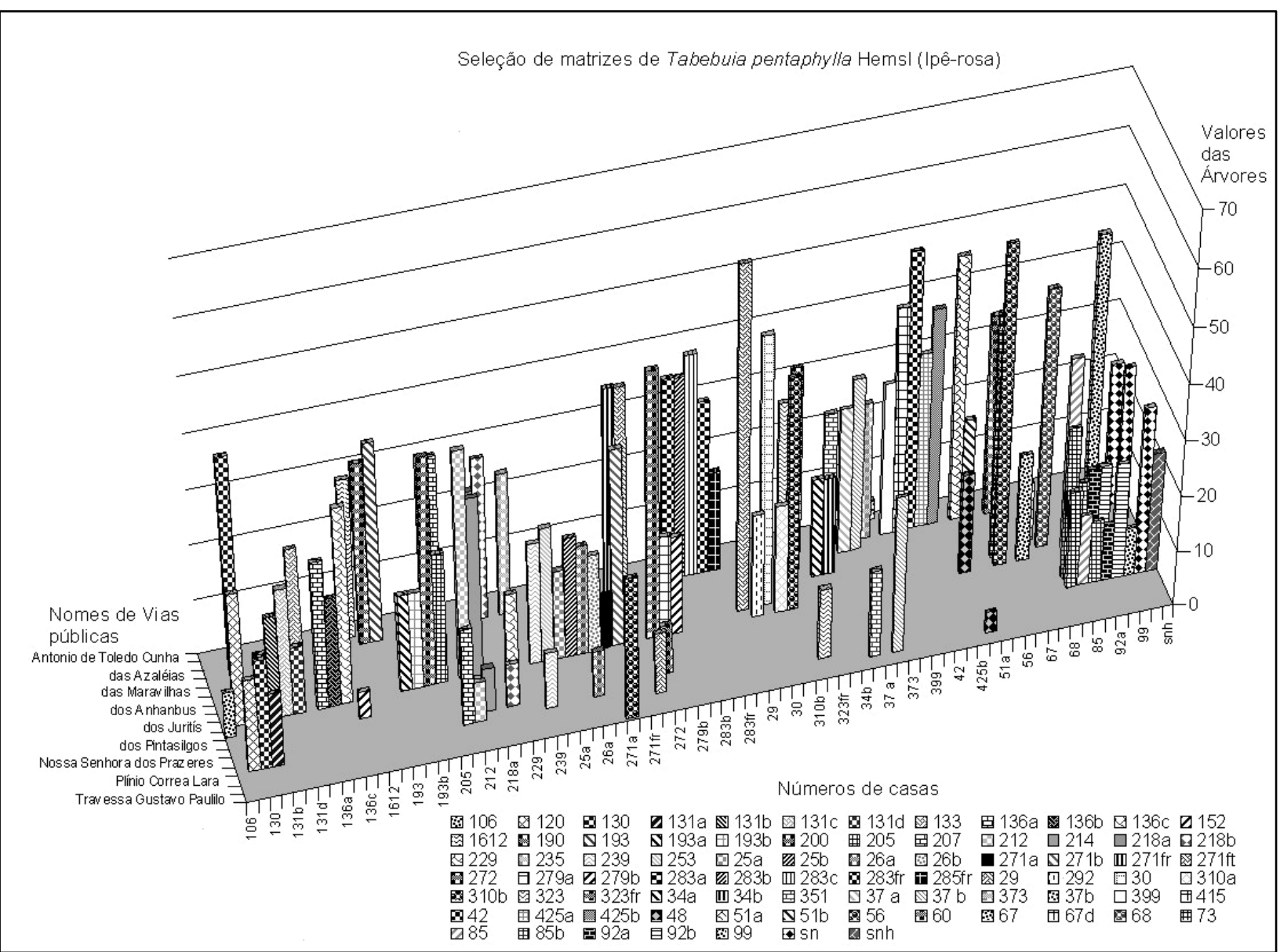

Figura 4: Índice de Importância (li) de cada indivíduo da espécie Ipê-Rosa-Americano (Tabebuia pentaphylla (L.) Hemsl.), o logradouro e o número do lote onde está localizado. 


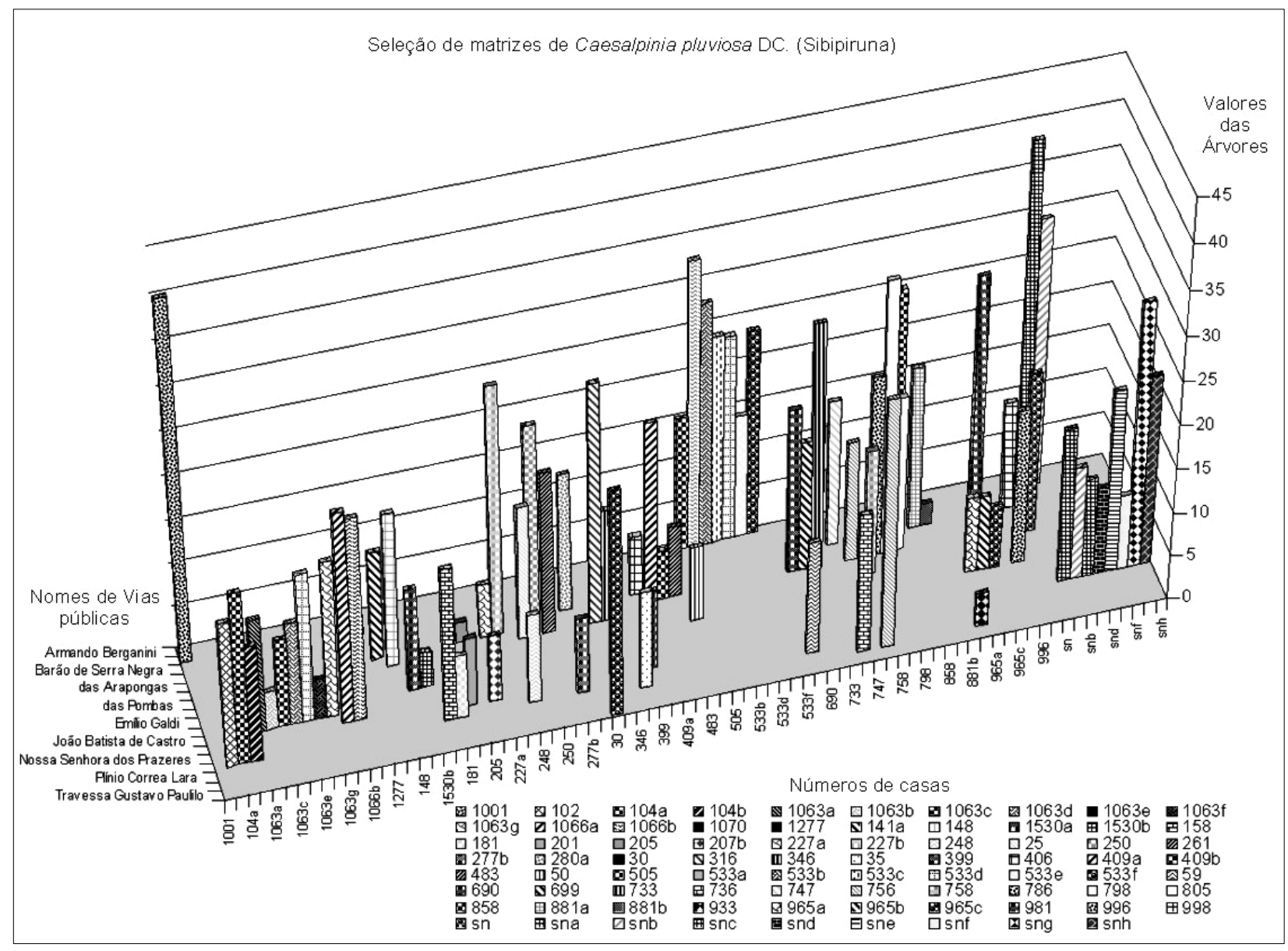

Figura 5: Índice de Importância (li) de cada indivíduo da espécie Sibipiruna (Caesalpinia pluviosa DC), o logradouro e o número do lote onde está localizado.

O fato de um indivíduo apresentar um valor maior de li, não significa que a sua performance seja a máxima que possa ser atingida no ambiente urbano pela espécie. Isto só pode ser alcançado pela introdução de novo material genético e de adequadas práticas de implantação e manejo.

Sugere-se a utilização dos valores de li para o manejo e planejamento da arborização viária, pois esse reflete a atual situação de interação entre os indivíduos e o ambiente urbano. Isto pode ser feito comparando-se os indivíduos de uma mesma espécie pelo valor do índice. Espécies diferentes não podem ser comparadas, pois essas apresentam características físicas próprias, como por exemplo, diâmetro de copa. Logo, uma espécie que apresenta um índice maior que outra não necessariamente possui melhor interação com o ambiente urbano.

O planejamento deve constantemente buscar a máxima diversificação de espécies em freqüências equilibradas, visando a otimização da qualidade ecológica da floresta urbana. 
Milano \& Dalcin (2000) recomendam que sejam utilizadas entre 10 e 20 espécies para constituir a arborização de uma cidade. Em locais de clima temperado, visando a proteção da floresta urbana da infestação de pragas e doenças, é sugerido que sejam utilizadas quantidades que resultem em freqüências relativas de espécies menores que $10 \%$, de gêneros menores que 20\% e de famílias menores que 30\% (Santamour Junior, 1990). Grey \& Deneke (1978) recomendam que essa esteja entre $10 \%$ e $15 \%$ por espécie.

Cabe salientar que o ambiente tropical contém grande diversidade de espécies arbóreas, sendo encontradas até 200 por hectare; enquanto que em florestas temperadas essa quantidade é da dimensão de algumas dezenas (Kageyama \& Gandara, 1993).

Essa riqueza em diversidade possibilita uma altíssima quantidade de interações entre os organismos presentes nesse ambiente, aumentando a probabilidade de aparecimento de pragas e doenças em um sistema com baixa diversidade. Portanto, sugere-se que a quantidade de espécies a ser definida no planejamento proporcionem freqüências relativas inferiores àquelas normalmente utilizadas, buscando-se constantemente a máxima diversificação possível e a aproximação com o ambiente natural. Zerbe et al. (2003) apontam que para se alcançar a conservação da natureza e o desenvolvimento sustentável, é necessário levar em consideração a biodiversidade objetivando a paisagem urbana com maior diversidade de espécies.

Por meio de monitoramentos da floresta urbana e a atualização do cadastro, os indivíduos classificados como matrizes potenciais poderão ser novamente ordenados. Da mesma forma, novos indivíduos poderão ser definidos como matrizes por apresentarem valores de li superiores àqueles que haviam sido determinados originalmente.

Segundo a Natural Path Forestry Consultants citado por Couto (1994), o monitoramento, que é uma prática essencial para o manejo da floresta urbana, ainda apresenta outras vantagens como a avaliação das ações executadas; a definição de novas prioridades e recursos necessários; a detecção de alterações na estrutura etária, da diversidade de espécies e das quantidades existentes em relação ao espaço que as comporta; a antecipação e a correção de futuros problemas; a avaliação e o controle das atividades de manejo utilizadas; a revelação de indivíduos e/ou espécies que apresentam menores taxas de sobrevivência e melhor adaptabilidade ao meio e; a descoberta da presença de pragas e doenças, possibilitando o seu controle com maior eficácia.

As características apresentadas pelos indivíduos componentes da floresta urbana são os resultados de práticas de condução durante a fase de produção de mudas, podas, poluição, insolação, nutrição, entre outras. Essa gama de fatores varia em quantidade e intensidade 
conforme o local onde os indivíduos foram implantados.

Visando o melhoramento genético, esses fatores poderiam ser considerados como sendo fatores ambientais e deveriam estar presentes uniformemente em todos os indivíduos. Como no ambiente urbano há grande variação de ambientes e situações, o melhoramento genético por seleção de fenótipos torna-se impraticável nessa situação. Por exemplo, não é válido afirmar que as melhores condições de vigor apresentadas por um indivíduo em relação a outro é resultante apenas do seu genótipo, pois esse indivíduo pode ter sido favorecido por circunstâncias especiais. Contudo, ao se identificar indivíduos com características desejáveis em Silvicultura Urbana, há alguma probabilidade de estarem sendo selecionados indivíduos que apresentam melhor adaptação a esse ambiente.

\section{Espécies de estudo}

Apenas duas espécies arbóreas apresentaram a freqüência suficiente para que fosse realizada a demarcação das matrizes a Caesalpinia pluviosa DC. e Tabebuia pentaphylla (L.) Hemsl.

\section{Definição do mapa de coleta de sementes}

Para a elaboração do mapa, foi realizada a mensuração da distância entre os indivíduos e a esquina. Esses valores, assim como o diâmetro das respectivas copas foram plotados com o auxílio do software AutoCAD 13, para a locação espacial dos indivíduos no mapa da área estudada. O mapa de coleta pode ser visualizado na Figura 6. 


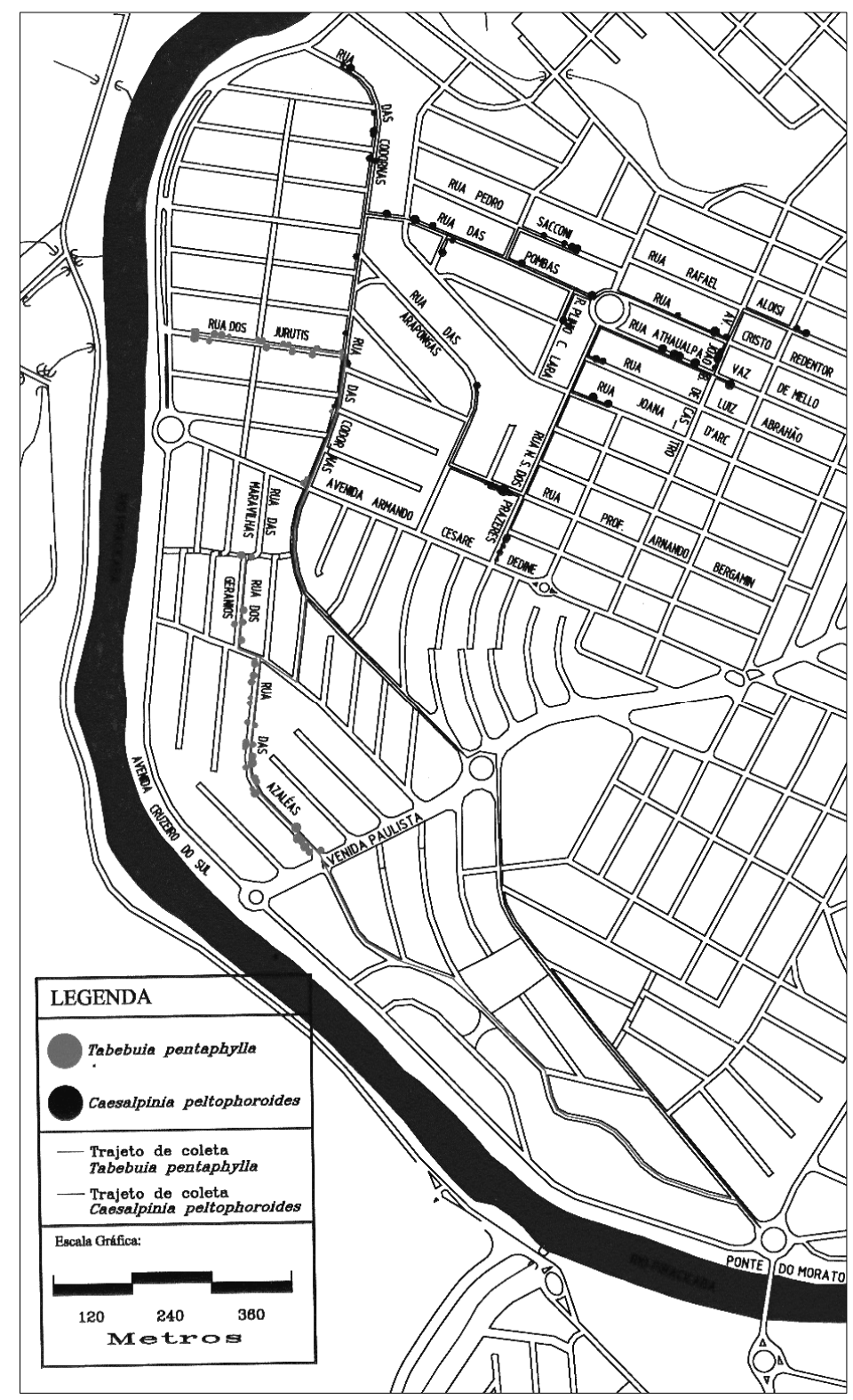

Figura 6: Mapa de coleta de sementes a ser percorrido, com a localização dos indivíduos e as copas proporcionais às dimensões reais.

\section{CONCLUSÕES}

- O estudo demonstrou que a determinação de matrizes urbanas por meio do índice de importância proporciona eficiência ao se eleger indivíduos por meio de vários parâmetros quali-quantitativos simultaneamente. Ainda, com a sua atualização, podem ser determinadas novas matrizes com relativa facilidade.

- A introdução de novos indivíduos que representem incremento na variabilidade genética das 
populações, provavelmente, proporcionará melhores performances de indivíduos. Esses novos indivíduos podem ser oriundos de outras cidades o que irá melhorar a segurança no incremento da variabilidade.

\section{AGRADECIMENTO}

Os autores agradecem a Fundação de Amparo á Pesquisa do Estado de São Paulo pelo apoio recebido em projeto na linha de políticas públicas para realização desta pesquisa.

\section{REFERÊNCIAS BIBLIOGRÁFICAS}

BAWA, K.S. Breeding systems of tree species for a lowland tropical community. Evolution, v.28, p.85-92, 1973.

BREWBAKER, J.L. Genética na Agricultura. Trad. de J.T. do A. Gurgel \& R. Vencovsky. São Paulo: Polígono e Editora da Universidade de São Paulo, 1969. 224p.

CASTELLEN, M.S. Uso de Marcadores RAPD e Isoenzimáticos na quantificação da diversidade genética em populações naturais de Esenbeckia leiocarpa Engl. Piracicaba, 2000. 76p. Dissertação (Mestrado) - Escola Superior de Agricultura "Luiz de Queiroz", Universidade de São Paulo.

COUTO, H.T.Z. Métodos de amostragem para a avaliação de árvores de ruas. In.: II Congresso Brasileiro de Arborização Urbana, São Luís, 1994. Resumos. São Luís, 1994. p.431-436.

FRANKEL, O. H.,\& M. E. SOULÉ. Conservation and evolution. Cambridge University Press, Cambridge, UK, 1981. 327p.

IBGE - INSTITUTO BRASILEIRO DE GEOGRAFIA E ESTATÍSTICA. STATCART: base de informações por setor censitário, Piracicaba, SP - Censo Demográfico 2000. Rio de Janeiro, 2002. 1 CD-ROM.

KAGEYAMA, P.Y. \& GANDARA, F.B. Dinâmica de populações de espécies arbóreas: implicações para o manejo e a conservção. In: III Simpósio de Ecossistemas da costa brasileira: subsídios a um gerenciamento ambiental, v.2, Serra Negra, SP, 1994. Anais. Serra 
Negra: ACIESP, 1994. p.1-9.

KATO, C.M.; AUAD, A.M.; BUENO, V.H.P. Aspectos biológicos e etológicos de Olla v-nigrum (Mulsant, 1866) (Coleoptera: Coccinellidae) sobre Psylla sp. (Homoptera: Psyllidae). Ciências Agrotécnica, v.23, n.1, p.19-23, jan/mar., 1999.

MENEGHETTI, G.I.P. Estudo de dois métodos de amostragem para inventário da arborização de ruas dos bairros da orla marítima do município de Santos, SP. Piracicaba, 2003. 100p. Dissertação (Mestrado) - Escola Superior de Agricultura "Luiz de Queiroz", Universidade de São Paulo.

SANTAMOUR JÚNIOR, F.S. Trees for urban planting: diversity uniformity, and common sense. In: METRIA CONFERENCE, 7., Lisle. 1990. Proceedings. Lisle: 57-66, 1990.

SEBBENN, A.M. Número de árvores matrizes e conceitos genéticos na coleta de sementes para reflorestamentos com espécies nativas. Revista do Instituto Florestal, v.14, n.2, p.115132, 2002.

SEBBENN, A.M.; KAGEYAMA, P.Y.; VENCOVSKY, R. Estrutura genética de subpopulações de Genipa americana L. (Rubiaceae) em mata ciliar a partir de isoenzimas. Revista do Instituto Florestal, v.10, n.1, p.95-108, 1998.

SHIMIZU, J.Y. Memórias do "workshop" sobre conservação e uso de recursos genéticos florestais. Documentos EMBRAPA, n.56., p.18-66, Outubro, 2001.

SILVA FILHO, D.F.; PIZETTA, P.U.C.; ALMEIDA, J.B.S.A. de; PIVETTA, K.F.L.; FERRAUDO, A.S. Banco de dados relacional para cadastro, avaliação e manejo da arborização em vias públicas. Revista Árvore. Viçosa. v.26, n.5, p.629-642, 2002.

SILVA FILHO, D.F. da. Aplicação de videografia aérea multiespectral na avaliação de floresta urbana. 2004. 88 f. Tese (Doutorado em Agronomia) - Faculdade de Ciências Agrárias e Veterinárias, Universidade Estadual Paulista, Jaboticabal, 2004.

VENCOVSKY, R. Tamanho efetivo populacional na coleta e preservação de germoplasmas de espécies alógamas. IPEF, v.35, p.79-84, Abril. 1987. 
WIKIPÉDIA. Município de Piracicaba - A Noiva da Colina. http://pt.wikipedia.org/wiki/Piracicaba (20 set. 2007)

ZERBE, S.; MAURER, U.; SCHMITZ, S.; SUKOPP, H. Biodiversity in Berlin and its potential for nature conservation. Landscape and urban planning, v.62, p.139-148, 2003. 